\title{
The Design and Validation of the Colorado Learning Attitudes about Science Survey
}

\author{
W. K. Adams, K. K. Perkins, M. Dubson, N. D. Finkelstein and C. E. Wieman \\ Department of Physics, University of Colorado, Boulder, Colorado 80309
}

\begin{abstract}
The Colorado Learning Attitudes about Science Survey (CLASS) is a new instrument designed to measure various facets of student attitudes and beliefs about learning physics. This instrument extends previous work by probing additional facets of student attitudes and beliefs. It has been written to be suitably worded for students in a variety of different courses. This paper introduces the CLASS and its design and validation studies, which include analyzing results from over 2400 students, interviews and factor analyses. Methodology used to determine categories and how to analyze the robustness of categories for probing various facets of student learning are also described. This paper serves as the foundation for the results and conclusions from the analysis of our survey data [4][5].
\end{abstract}

\section{INTRODUCTION}

Over the last decade, researchers in science education have identified a variety of student attitudes and beliefs (ABs) that shape and are shaped by student classroom experience[1]. Over the last year at Colorado, we have developed and validated an instrument, the Colorado Learning Attitudes about Science Survey, CLASS[2], which builds on existing surveys (MPEX, VASS, EBAPS)[3]. This survey probes student's $\mathrm{ABs}$ and distinguishes the $\mathrm{ABs}$ of experts from novices. The CLASS was written to make the statements as clear and concise as possible and is readily adapted to use in a wide variety of science courses. Students are asked to respond on a Likert-like (5-point agree to disagree) scale to statements such as: "I study physics to learn knowledge that will be useful in life.", or "After I study a topic in physics and feel that I understand it, I have difficulty solving problems on the same topic.", or "To learn physics, I only need to memorize important equations and definitions." In this paper we will discuss the methods used to validate the survey. We will also discuss the subtleties of choosing categories of statements and list the seven categories we have chosen. The survey has generated some very interesting results which are discussed briefly here and in depth in the companion papers by Perkins et al.[4] and Pollock[5].

\section{DESIGN AND ADMINISTRATION}

The CLASS was designed for use with a broad population, takes only ten minutes to complete and covers many areas of student's ABs about physics. To make it suitable for a variety of courses serving nonscience majors, physics majors or graduate students words such as "domain" or "concepts", which are not prevalent in a typical introductory student's vocabulary, were avoided. Every effort was made to avoid statements that include two different statements. Finally, one of the most difficult tasks was creating statements that were interpreted in only one way by both faculty and students.

Students (though perhaps not physicists) use the word physics in at least three ways: a particular course, the scientific discipline, or the physics that describes nature. We designed the survey to embrace a single meaning of the word physics to avoid confusion. We focused the statements on physics that describes nature; noting this sense sometimes overlaps with physics as a discipline. By taking this approach, it made the statements meaningful even if a student had never taken a physics course.

This survey has been administered before (pre) and after (post) instruction to 2400 students in 10 courses over the past year either online or paper and pencil. Scoring is done by determining the percentage of a group of students who agree with the experts' view. We calculate the overall score and then in the five categories listed in Table 2. Each category consists of 
three to eight statements that correlate with one another and target a specific attitude or belief about science.

\section{VALIDITY AND RELIABILITY}

Validation was done in three steps: First experts were interviewed and then took the survey; second students were interviewed to confirm the clarity and meaning of statements; and finally a detailed factor analysis was performed to create and verify existing categories of statements.

Three experts underwent a series of interviews on the initial draft of CLASS V.1 (Version 1 - Fall 2003). Their comments were used to hone the statements and remove any that could be interpreted more than one way. When this process was complete, seven experts took the survey. Their answers confirmed the expert point of view used in scoring. These experts were physicists who have extensive experience with teaching introductory courses and worked with thousands of students. Some of these experts are involved with physics education research; others are simply practicing physicists interested in teaching. The experts provided consistent responses to all statements in V.2 (Version 2 - Spring 2004) except to three statements, none of which are included in the final five categories.

Student interviews were carried out by obtaining 34 volunteers from six different courses at a mid-size multipurpose state university (MMSU) and a large state research university (LSRU). Care was taken to acquire a diverse group of interviewees. Interviews consisted of first having the student take the survey with pencil and paper. Then, during the first ten minutes, students were asked about their major, course load, best/worst classes, how they study, class attendance and future aspirations to characterize the student and their interests. After this, the interviewer read the statements to the students while the student looked at a written version. The students were asked to answer each statement using the 5-point scale and then talk about whatever thoughts each statement elicited. If the student did not say anything, he/she was prompted to explain his/her choice. After the first five or six statements, the students no longer required prompting. If the students asked questions of the interviewer, they were not answered until the very end of the interview.

Interview results showed students and experts had consistent interpretations on nearly all of the statements. A few statements were unclear or misinterpreted by some of the students. Some of these were reworded or removed for V.2. and the remainder were addressed with V.3. (Version 3 - Fall 2004). Finally there were statements that elicited unexpected student ideas, which will be used for further refinement of the survey.

Statistical analyses were used to test the validity of the sub-groupings of statements into categories. We performed a factor analysis, a data reduction technique that groups similar statements using correlations

TABLE 1. Reduced Basis Factor Analysis of Categories - CLASS Version 2

\begin{tabular}{|c|c|c|c|c|c|}
\hline $\begin{array}{l}\text { Predetermined } \\
\text { Categories }\end{array}$ & $\begin{array}{c}\text { FA } \\
\text { Results }\end{array}$ & Optimum categories & $\begin{array}{l}\text { Emergent } \\
\text { Categories }\end{array}$ & $\begin{array}{c}\text { FA } \\
\text { Results }\end{array}$ & Optimum categories \\
\hline Independence & MF & $\begin{array}{l}\text { Conceptual } \\
\text { Understanding }\end{array}$ & Category 1 & SS* & $\begin{array}{l}\text { Real World Conn. and } \\
\text { Personal Interest }\end{array}$ \\
\hline Coherence & $\mathrm{PC}$ & $\begin{array}{l}\text { Conceptual } \\
\text { Understanding }\end{array}$ & Category 2 & SS* & $\begin{array}{l}\text { Real World Conn. and } \\
\text { Personal Interest }\end{array}$ \\
\hline Concepts & MF & $\begin{array}{l}\text { Conceptual } \\
\text { Understanding }\end{array}$ & Category 3 & BQ & Conceptual Understanding \\
\hline $\begin{array}{l}\text { Reality World } \\
\text { View }\end{array}$ & SS & Real World Connection & Category 4 & WF & Dropped \\
\hline $\begin{array}{l}\text { Reality Personal } \\
\text { View }\end{array}$ & SS & Personal Interest & Category 5 & NS & Dropped \\
\hline Math & SS & $\begin{array}{l}\text { Math Physics } \\
\text { Connection }\end{array}$ & Category 6 & SS & Sense Making/Effort \\
\hline Effort & $\mathrm{PC}$ & Sense Making/Effort & Category 7 & WF & Dropped \\
\hline Skepticism & $\mathrm{PC}$ & Dropped & & & \\
\hline \multicolumn{6}{|c|}{$\begin{array}{l}\mathrm{SS}=\text { Strong Single Factor; } \mathrm{BQ}=\text { Better } \mathrm{w} / 1 \text { or } 2 \text { different statements; } \mathrm{WF}=\text { Weak Factor; } \mathrm{NS}=\text { Statements } \\
\text { didn't make sense together; } \mathrm{MF}=\text { Multiple factors; } \mathrm{PC}=\text { Poorly Correlated }\end{array}$} \\
\hline
\end{tabular}


between statement responses. We used the principle components extraction method along with a direct oblimin rotation and performed both an exploratory and a confirmatory factor analysis. For more detail on factor analysis see reference [6].

First, we did an exploratory factor analysis, which analyzes the results from all statements and then groups statements that were answered similarly by students into independent factors. The exploratory factor analysis was performed with V.2 of the survey on three sets of data from a calculus-based physics I course ( $\mathrm{N}=416)$ : pre-test results, post-test results and the shift from pre to post. The results from this exploratory factor analysis provided a set of independent, emergent categories. These provide an oblique basis set that best spans the space of student responses.

Another useful perspective is to look at specific groups of statements that probe facets of learning that the physics professor can directly address. Following this idea we chose our original categories based on the categories used by the MPEX and the VASS and expanded upon them slightly during the first two phases of validation of the CLASS (predetermined categories). Such categories emphasize what a physicist believes is useful for learning physics (expert perspective) rather than emphasizing the way students think (student perspective). This means that some of these categories may not be independent of one another; however, if statements are properly designed, these categories are still self-consistent and provide useful information.

Next, we performed a reduced basis factor analysis using the predetermined categories and the emergent categories. With this technique a factor analysis is performed using a basis set that is limited to those statements we believe should be in the category plus a small number of additional statements that are candidates for the category based on their correlations. After carrying out a reduced basis factor analysis, we evaluate the scree plots, correlation coefficients, and factor loadings to determine the categories "robustness". Multiple iterations of this analysis and adding/subtracting statements are used to optimize the categories. After determining robust categories in this

TABLE 2. CLASS Version 2 Categories

\begin{tabular}{lc}
\hline Category & Robustness \\
\hline Personal Interest & 7.75 \\
Reality World Connection & 7.38 \\
Math Physics Connection & 6.51 \\
Conceptual Understanding & 6.11 \\
Sense Making/Effort & 5.89 \\
\hline Robustness Ratings done for calculus-based Physics I students \\
at LSRU.
\end{tabular}

fashion, we evaluate the statements not included in any category and search for new categories by looking specifically for correlations with those statements. Table 1 above illustrates the categorization process. Results of this analysis on CLASS V.2 provided the five very robust, albeit not completely independent, categories shown in Table 2.

Reliability studies were conducted in Calculusbased physics I at LSRU which is offered every semester with an enrollment over 500 students. During the 2003-2004 school year the course was taught by the same professor, who allowed us to administer the survey to his course pre and post, both Fall and Spring semester. The pre and post results for the two semesters were not statistically different for statements that were the same on both surveys. See Table 3 for overall scores, Real World Connection and Math Physics Connection for both Fall and Spring semesters.

TABLE 6. Reliability Data

\begin{tabular}{|c|c|c|c|}
\hline Category & Pre & Post & Std. Err. \\
\hline \multicolumn{4}{|l|}{ Fall } \\
\hline Overall & $66 \%$ & $67 \%$ & $1 \%$ \\
\hline Real World Connections & $74 \%$ & $77 \%$ & $2 \%$ \\
\hline Sense Making/Effort & $77 \%$ & $68 \%$ & $2 \%$ \\
\hline \multicolumn{4}{|l|}{ Spring } \\
\hline Overall & $68 \%$ & $70 \%$ & $1 \%$ \\
\hline Real World Connections & $74 \%$ & $79 \%$ & $1 \%$ \\
\hline Sense Making/Effort & $78 \%$ & $71 \%$ & $1 \%$ \\
\hline
\end{tabular}

\section{APPLICATIONS}

There are several useful ways to use the scores from the CLASS. One can look at the pre-test results and their influence on student learning or retention. One can also look at the change in attitudes over a semester to determine what effect instruction had on students' ABs. In Table 4 we show results for six courses covering a range of introductory physics courses. We see that students' incoming 'Personal Interest' increases with level of physics course. Thus, students who make larger commitments to studying physics tend to be those who identify physics as being relevant to their own lives. As seen with other surveys, the CLASS shows student ABs deteriorate after instruction; unless, ABs are explicitly addressed by the instructor. We see in Table 4 that in the courses at LSRU, which explicitly attended to ABs, the overall scores did not deteriorate; however, in the courses at MMSU there was a substantial decline in ABs. A companion paper by Perkins et al.[4] goes into more detail on these courses and also carefully looks at 
TABLE 4. Evident correlation between favorable 'Personal Interest' and physics course selection

\begin{tabular}{|c|c|c|c|c|c|c|}
\hline \multirow[t]{2}{*}{ Course Type } & \multirow{2}{*}{$\begin{array}{c}\text { School } \\
\text { Type/Term }\end{array}$} & \multirow{2}{*}{$\begin{array}{l}\text { Dominant } \\
\text { student } \\
\text { population }\end{array}$} & \multirow[t]{2}{*}{$\mathbf{N}$} & \multicolumn{2}{|c|}{ Overall \%favorable } & \multirow{2}{*}{$\begin{array}{c}\text { Personal Interest } \\
\text { \%favorable on Pre-test } \\
\text { (Std. Error of Mean) }\end{array}$} \\
\hline & & & & Pre & Post & \\
\hline Non-Sci-I & $\mathrm{LSRU} / \mathrm{Fa03}$ & non-sci & 76 & $57 \%$ & $58 \%$ & $54 \%(4 \%)$ \\
\hline Non-Sci-II & LSRU/Sp04 & non-sci & 36 & $71 \%$ & $72 \%$ & $69 \%(5 \%)$ \\
\hline Alg-I & MMSU/Fa03 & pre-meds & 35 & $63 \%$ & $53 \%$ & $55 \%(3 \%)^{*}$ \\
\hline Calc-I & LSRU/Fa03 & engineers & 168 & $65 \%$ & $67 \%$ & $70 \%(2 \%)$ \\
\hline Calc-I & LSRU/Sp04 & engineers & 398 & $68 \%$ & $70 \%$ & $72 \%(1 \%)$ \\
\hline Calc-I & MMSU/Fa03 & physics maj & 38 & $65 \%$ & $57 \%$ & $74 \%(4 \%)$ \\
\hline
\end{tabular}

correlations of students' ABs with their learning gains. They show that students with large learning gains have a greater positive shift in $\mathrm{ABs}$ while students with lower learning gains show a deterioration in $\mathrm{ABs}$.

\section{CONCLUSIONS AND FURTHER WORK}

This paper describes the philosophy and methods behind the development of the CLASS. In addition we detail the validity and reliability studies for this survey. We also define a process of selecting categories of statements and determining their robustness. This paper serves as the foundation for the results and conclusions from the analysis of our survey data and future applications of the survey.

Analysis and refinement of the CLASS is still in process. Over the next year we plan to perform a factor analysis of the results for other courses, a final revision of the current statements and creation of statements to target other categories that were not adequately addressed by the current version of the survey. The survey will also be altered slightly to be appropriate for use in Biology, Math, Astronomy and Chemistry and administered to these courses this Fall. Finally we would like to step beyond simply characterizing groups of students to identifying individual student characteristics.

Note added in proof: CLASS Version 3 and a listing of questions by category can be found at http://cosmos.colorado.edu/phet/survey/CLASS/.

\section{ACKNOWLEDGMENTS}

Thank you to Steven Pollock and Courtney Willis for many helpful discussions and the members of the PER@C group. This work is supported, in part, by the NSF.

\section{REFERENCES}

[1] Bransford, J.D., Brown, A.L., and Cocking, R.R. (2002). How People Learn Washington D.C.: National AcademyPress.

Hammer, D. (2000) Student resources for learning introductory physics, American Journal of Physics, 68, S52-S59.

Redish, E.F.,(2003). Teaching Physics with Physics Suite, John Wiley \& Sons. Seymour, E. and Hewitt, N.,(1997). Talking about Leaving, Westview Press.

[2] A copy of the CLASS V.3 can be found at http://cosmos.colorado.edu/phet/survey/CLASS/

[3] Redish, E., Saul, J.M. and Steinberg, R.N. (1998). Student Expectations in Introductory Physics American Journal of Physics, 66, 212-224. www.physics.umd.edu/perg/expects/index.html Halloun, I. A. "Views About Science and Physics Achievement: The VASS Story." In The Changing Role of Physics Departments in Modern Universities: Proceedings of the ICUPE, E.F. http://modeling.asu.edu/R\&E/Research.html

Elby, A., Epistemological Beliefs Assessment for Physical Science. http://www2.physics.umd.edu/ elby/ EBAPS/home.htm

[4] Perkins, K., Adams, W., Finkelstein, N. and Wieman, C. (2004). Correlating student attitudes with student learning using the Colorado Learning Attitudes about Science Survey, submitted to PERC Proceedings 2004.

[5] Pollock, S.(2004). No Single Cause: Learning Gains, Student Attitudes, and the Impacts of Multiple Effective Reforms, submitted to PERC Proceedings 2004.

[6] Crocker, L. and Algina, J., (1986). Introduction to Classical and Modern Test Theory, Fort Worth: Hold, Rinehart and Winston, Inc.

Kachigan, S. K., (1986). Statistical Analysis, New York: Radius Press.

Kim, J. and Mueller, C. W., (1978). Factor Analysis Statistical Methods and Practical Issues, Beverly Hills: Sage Publications. 